\title{
SENTENÇAS JUDICIAIS QUE CONDENAM O ESTADO BRASILEIRO \\ À REALIZAÇÃO DE POLÍTICAS PÚBLICAS
}

\author{
Maria Carolina Florentino Lascala
}

carollascala@hotmail.com

Riva Sobrado de Freitas

rivafreit@ig.com.br

\begin{abstract}
RESUMO
$\mathrm{O}$ presente estudo analisa as sentenças judiciais que determinam ao Estado Brasileiro a realização de políticas públicas. Primeiramente, veremos alguns conceitos dados a "políticas públicas" e, desde logo, será possível concluir que elas são os meios de concretização dos direitos fundamentais. Após, será demonstrada a relação de cada um dos três poderes do Estado Democrático com as políticas públicas, com destaque para o controle judicial das mesmas. Serão vistos os limites e a eficácia das sentenças judiciais que se envolvem com questões naturalmente de mérito administrativo.
\end{abstract}

Palavras-chave: Políticas públicas - Divisão de poderes - Controle judicial.

\begin{abstract}
This paper analyzes the court rulings which determine the implementation of public policies by the Brazilian State. Firstly, some concepts given to "public policies" will be addressed and, immediately, it will be possible to conclude that they are means of achieving fundamental rights. After that, it will be demonstrated the relationship of each one of the three branches of the Democratic State with the public policies, highlighting their judicial control. The limits and effectiveness of court rulings involving issues of substantive administrative merit will be seen.
\end{abstract}

Keywords: Public policies - Separation of powers - Judicial control.

\section{INTRODUÇÃO}

Discutir políticas públicas é tratar de direitos fundamentais, já que aquelas são as ações governamentais objetivando à realização desses.

As principais diretrizes das políticas públicas brasileiras já estão previstas na Constituição Federal de 1988, que de forma programática cuidou de temas variados muito além da mera estrutura do Estado. 
No Brasil, muitas são as carências da população, ao passo que os recursos públicos são incapazes de atender de uma só vez a toda a demanda social. Por isso, há a necessidade de constante controle das políticas públicas por todos os órgãos estatais e mesmo pela sociedade civil para que haja a mais justa distribuição desses recursos.

Não raro, um indivíduo que se vê inatingido por um direito fundamental assegurado pela Constituição leva o litígio ao Judiciário e requer deste uma postura frente ao seu pleito. O juiz, então, pode chegar à conclusão de que o cidadão não está tendo seu direito fundamental reconhecido por causa de uma política pública ausente ou ineficaz.

Mais recentemente, o número de demandas exigindo determinadas condutas do Estado envolvendo políticas públicas aumentou em razão das ações coletivas propostas pelo Ministério Público.

Este controle judicial das políticas públicas enfrenta alguns limites, como o da divisão de poderes, da escassez dos recursos públicos e da discricionariedade do mérito administrativo, pois a decisão de aplicar determinada verba para atender uma ou outra demanda social compete, tipicamente, ao Poder Executivo e ao Poder Legislativo.

No entanto, as políticas públicas, enquanto atos administrativos ou normativos, estão sujeitas à análise judicial para se evitar abusos e desrespeito à Constituição.

Tendo como pano de fundo o modelo estatal brasileiro, que necessita intervir na economia e em vários outros ramos da sociedade para assegurar o convívio pacífico e minimamente digno de seus cidadãos, analisemos o papel dessas sentenças judiciais que, em verdade, buscam a realização dos direitos fundamentais.

\section{CONCEITUANDO POLÍTICAS PÚBLICAS}

Sem dúvidas, mais difícil do que conceituar políticas públicas é conseguir a sua implementação com sucesso na prática. Apesar desta dificuldade, muitos estudiosos das ciências jurídicas e principalmente das ciências políticas e sociais buscam a definição perfeita do instituto.

Sem tamanha pretensão, um conceito adequado seria o de conjunto de ações do Estado tendentes à realização dos direitos humanos.

Estas ações do Estado podem estar expressas em atos administrativos ou em atos normativos. Os atos administrativos, geralmente, são identificados pelos serviços públicos prestados diretamente pelo Estado ou sob sua ordem. Os atos normativos, por sua vez, podem 
ser dispositivos constitucionais, infraconstitucionais ou mesmo infralegais (portarias, decretos, resoluções, ...).

Vejamos o exemplo do direito à saúde. É um direito previsto constitucionalmente (art. 196), regulamentado pela Lei n. 8.080/90 que criou o Sistema Único da Saúde. É objeto de inúmeros outros atos normativos federais, estaduais e municipais, além de ser tutelado por serviço público prestado por órgãos e instituições públicas de todos os entes federativos, da administração direta e indireta, e ainda por particulares sob supervisão do Estado.

Mais especificamente, pode-se imaginar uma política pública municipal de vigilância epidemiológica do Aedes aegypti (mosquito transmissor da dengue), pela qual a prefeitura destina verba pública para a contratação de funcionários para visitar os imóveis de toda a cidade, orientando sobre a forma de eliminar os focos de criação do mosquito, bem como realizando a dedetização das ruas. Neste exemplo, pode haver ainda lei municipal programando esta vigilância epidemiológica. Então, esta política pública de combate ao mosquito da dengue se daria por atos normativos e administrativos, do poder legislativo e executivo municipal.

Para Fábio Konder Comparato (MASSA-ARZABE, 2006:45), política pública aparece antes de tudo como atividade, isto é, um conjunto organizado de normas e atos tendentes à realização de um objetivo determinado.

Para Patrícia Helena Massa-Arzabe (2006:63) políticas públicas são os conjuntos de programas de ação governamental estáveis no tempo, racionalmente moldados, implantados e avaliados, dirigidos à realização de direitos e de objetivos social e juridicamente relevantes, que buscam a distribuição e redistribuição de bens e posições que concretizem oportunidades para cada pessoa viver com dignidade e exercer seus direitos, assegurando-lhes recursos e condições para a ação, assim como a liberdade de escolha para fazerem uso desses recursos.

Não há também como dissociar o conceito de políticas públicas do conceito, igualmente difícil, de serviços públicos.

Para Ronaldo Jorge Araujo Vieira Junior (2009:33), políticas públicas são os conjuntos de programas, projetos e atividades promovidos pelo Estado, por intermédio de seus órgãos e entidades, destinados a ofertar bens e serviços à população de modo a tornar efetivos os direitos individuais, econômicos, sociais e ambientais previstos no texto constitucional e no ordenamento infraconstitucional.

É quase unânime entre os doutrinadores que a política pública passa pelas seguintes fases: formação, execução, controle e avaliação. Para a sua formação, é preciso uma equipe 
multidisciplinar, sendo indispensável ao menos um especialista sobre o problema social que se quer resolver, além do administrador e sua assessoria jurídica.

Ainda Ronaldo Jorge Araújo Vieira Junior (2009:34) apresenta sete componentes das políticas públicas que deveriam ser observados: a) competências dos órgãos e entidades na formulação, implementação e avaliação das políticas públicas; b) eventual articulação entre os órgãos do Estado; c) financiamento da política pública; d) mecanismos que viabilizem a participação popular; e) segmentos da população elegíveis para cada política; f) mecanismos de operacionalização; g) a avaliação, a realidade e a eventual redefinição das políticas públicas.

Realmente, quem deseja elaborar uma política pública precisa ser competente para tanto e não deve invadir a esfera de competência de outro órgão, sendo necessária, muitas vezes, a articulação política entre eles para a composição dos interesses envolvidos.

Como exemplo, cita-se uma rodovia interligando dois municípios no meio da Floresta Amazônica. De um lado, é certo o interesse público de dar acesso aos municípios e muito útil seria a construção da rodovia. Por outro, é de se considerar a preservação ambiental da área em que será feita a obra. Portanto, podem estar presentes nas negociações políticas: Ministério do Transportes, Ministério do Meio Ambiente, prefeituras dos municípios envolvidos, além do Governo do Estado, de modo a compatibilizar os interesses e chegar à solução mais apropriada.

Outro fator determinante da política pública é a sua forma de financiamento e, então, compete ao administrador gerenciar os recursos públicos de forma a alcançar o máximo de eficiência com o que se tem disponível. Para verificar se a política é adequada e eficaz, cabe ao segmento social atingido pela ação governamental opinar, expondo sua avaliação sobre o que fora realizado.

Além destes componentes, também é preciso haver "motivação" suficientemente provada para justificar a atuação estatal. Isso quer dizer que o Estado deve ter suporte probatório de que o emprego da verba pública naquela atividade/serviço é relevante. Este suporte probatório se dá com documentos e, principalmente, dados estatísticos.

Saber a porcentagem de analfabetos de um município e a quantidade de pessoas na fila de espera para atendimento oftalmológico no posto de saúde pode ser determinante entre a aplicação de certa verba pública na educação de base ou na saúde oftalmológica.

Algumas escolhas, apesar de discricionárias, devem ser justificáveis aos olhos de todos. Por exemplo, pode parecer desacertado o gasto público com uma escola técnica de 
mecânica se no município e região não há empresas que se interessariam por absorver esta mão-de-obra qualificada.

Em relação à importância de se conhecer numericamente a realidade social para a adoção de determinada política pública, o IBGE - Instituto Brasileiro de Geografia e Estatística desempenha papel fundamental, assim como outras entidades de pesquisa e estatística social confiáveis.

Portanto, para ser legítima, a escolha da política pública, apesar de discricionária, não pode ser arbitrária e deve esclarecer qual o critério de decisão utilizado para a solução do problema, considerando sempre o objetivo que se deseja alcançar.

Wanderley Guilherme dos Santos (1998:35), em seu texto sobre a trágica condição da política social, diz ser impossível encontrar um conceito que cubra apropriadamente a definição de política social ${ }^{1}$, mas apresenta o seguinte: “define-se, então, política social como o conjunto de atividades ou programas governamentais destinados a remediar as falhas do laissez-faire".

De fato, somente faz sentido falar em política social nos Estados intervencionistas, que tentam realizar o princípio da igualdade material, minimizando as diferenças sociais e distribuindo de forma equânime os recursos disponíveis.

O autor confirma que, durante séculos, soube-se que os recursos disponíveis em qualquer sociedade eram insuficientes para satisfazer os desejos de todos os seus membros e que, nas sociedades modernas, o dilema está entre a equidade (justiça) e a eficiência (administração da escassez), o que leva à conclusão de que toda escolha social é uma escolha trágica no sentido radical de que, mesmo decisões altamente benéficas reverberam, em algum lugar, metamorfoseadas em mal. Vejamos sua melancólica conclusão (1998:37):

\footnotetext{
Por exemplo, a decisão de produzir $x$ aparelhos de hemodiálise significa não apenas que parcela de necessitados não terão acesso a eles, mas também que carentes de outro tipo não poderão usufruir de, digamos, tratamento com bombas de cobalto. Mais: se se decide produzir aparelhos de hemodiálise em número suficiente para atender à demanda, maior será o número de cancerosos desassistidos. Quanto produzir e o quê converte-se, por se saber algo mais, em outra questão: como estabelecer justo intercâmbio entre o bem e o mal? A política social escapa ao cálculo econômico e ingressa na contabilidade ética, no cerne do conflito entre valores, no trágico comércio entre o bem e o mal.
}

\section{DAS DIFICULDADES DE EXECUÇÃO DAS POLÍTICAS PÚBLICAS}

\footnotetext{
${ }^{1}$ Alguns autores tratam "política social” como sinônimo de "política pública".
} 
Muitas vezes, na formulação de uma política pública deve-se considerar que a solução buscada envolve indiretamente vários outros problemas sociais, positiva ou negativamente, o que leva o administrador público a ser um mediador de todas essas questões.

Por conseguinte, muitas demandas sociais não vão ser solucionadas exclusivamente pela adoção desta ou daquela política pública, nem mesmo por destinação de maior volume de recursos financeiros a elas.

Cito como exemplo hipotético o elevado número de mortes infantis em determinado município. Verificada a inexistência de saneamento básico no município, associada ao baixo grau de instrução da população e o costume religioso local que desvia as crianças do atendimento hospitalar para métodos curandeiros nada eficientes cientificamente, conclui-se que pouco adiantaria alto investimento no campo da saúde isoladamente. Neste caso, a mortalidade infantil seria reduzida somente com uma ação coordenada no campo da saúde, educação e planejamento urbanístico.

Portanto, é preciso identificar a demanda social e todas as suas circunstâncias, evitando-se despender demasiadamente recursos naqueles problemas gerados por outros, os quais seriam a sua verdadeira causa. Ou seja, é preferível investir mais em problemas sociais que são geradores de outros a investir em políticas públicas paliativas.

Aliás, quanto mais se tenta remediar problemas-produto ${ }^{2}$, mais lento será o processo de sensibilização para a real origem do problema-causa e consequente retificação de cursos ou modificação nas prioridades governamentais (SANTOS, 1998:53).

Não se quer dizer que políticas públicas paliativas sejam desnecessárias, mas que a maior parte do orçamento deve ser destinada à solução dos problemas sociais que são origens de outros.

Logo, investir no ensino superior e em escolas profissionalizantes é uma forma de se tentar amenizar o problema do desemprego. Canalizar o esgoto e fornecer água potável à população é uma forma de promoção da saúde. Investir em vacinas gera a redução de custos futuros com o tratamento de doenças. Conservar uma praça pública, construindo uma quadra de jogos ao ar livre e investir na iluminação do bairro, pode ser um meio de se reduzir a violência urbana.

Sobre a motivação da escolha do critério utilizado para a tomada de decisões administrativas, o que legitima a política pública, ainda o autor Wanderley Guilherme dos

\footnotetext{
2 “problema-produto" é uma expressão utilizada por Wanderley Guilherme dos Santos
} 
Santos (1998:52) dá um exemplo bastante ilustrativo, provando que, na democracia, há distribuição de sacrifícios e benefícios:

É possível analisar as políticas de saneamento básico e de assistência médica à infância e decidir que devem se pautar pelo princípio dos direitos absolutos - o que significa, na prática, que entre as alternativas de oferecer ambos os serviços de forma qualitativamente superior, porém limitados a determinadas áreas geográficas do país, ou proporcioná-los a todo o país, embora de qualidade inferior, não há razão legítima e plausível para optar pela primeira alternativa. Ao contrário, seria perfeitamente legítimo - segundo o princípio de direitos absolutos - distribuir universalmente os recursos disponíveis para tais políticas, compartilhando a população das conveniências desta igualdade distributiva, justamente pela ausência de critérios que permitam discriminar positiva ou negativamente esta ou aquela área geográfica.

Enfim, conforme a realidade social, deve-se buscar a melhor maneira de se empregar o dinheiro público, o que significa buscar eficiência.

Em alguns países desenvolvidos, não faz sentido haver uma rubrica orçamentária para determinada política pública, pois já não existe mais a carência social que a justifique. Esta é a tendência dos países que se posicionam firmemente na solução dos problemas sociais que dão origem a outros, porque enfrentando os problemas que estão na base estaremos eliminando o foco de proliferação daqueles que estão no topo.

Por pertinência ao tema, vale ainda analisarmos como Wanderley Guilherme dos Santos (1998:58) classifica as políticas sociais em preventivas, compensatórias e redistributivas:

Por política social preventiva entende-se qualquer política que impeça ou minimize a geração de um problema social grave. Por exemplo: saúde pública, saneamento básico, educação, nutrição, habitação, emprego e salário. A rubrica política compensatória compreende os programas sociais que remediam problemas gerados em larga medida por ineficientes políticas preventivas anteriores ou por políticas contemporâneas que são prima facie socialmente não-dependentes (políticas viárias, de transportes, etc.) - por exemplo, sistema previdenciário e PIPMO. Políticas redistributivas, finalmente, são programas que implicam efetiva transferência de renda dos patamares superiores para os patamares inferiores da estratificação social - por exemplo, Funrural e PIS/PASEP.

A partir desta classificação, é interessante analisar a forma de financiamento das políticas públicas. No tocante às políticas preventivas, parece justo que todos contribuam para a sua realização, via sistema tributário. Já no caso das políticas compensatórias, não pode haver a distribuição do ônus, havendo soluções distintas para cada caso. Assim, não parece certo que um benefício de acidente de trabalho seja pago pelo Estado, pelo empregador e pelo próprio acidentado! Finalmente, as políticas redistributivas implicam em transferência de renda e é absolutamente certo que não são os beneficiários delas quem as deve financiar (SANTOS, 1998:61). 
Deste modo, a Constituição Brasileira de 1988, em razão das circunstâncias históricas pós-ditadura militar, optou por prever em seu texto muitas das políticas públicas a serem adotadas pelo Estado, indicando, às vezes, a sua forma de financiamento.

Assim, nosso constituinte originário previu o seguro-desemprego, a previdência social, a assistência social, a reforma agrária, a política urbana, a política ambiental, a política indigenista, a saúde, a educação, a proteção à criança e ao adolescente, etc. Por isso, nossa Constituição Federal é um programa de governo, ou melhor, é um programa de Estado.

Em razão da extensa lista de direitos fundamentais assegurados e da previsão das diretrizes de políticas públicas que devem ser adotadas pelos governantes para concretizar esses direitos, muitas vezes, o cidadão inassistido busca seu direito via Poder Judiciário.

\section{A DIVISÃO DE PODERES E AS POLÍTICAS PÚBLICAS}

Os três poderes do Estado, executivo, legislativo e judiciário, são independentes e harmônicos entre si. Tipicamente, ao poder executivo cabe a função de administrar, ao poder legislativo, a função de legislar e ao poder judiciário, a função de julgar. Pode parecer óbvio, mas esta conclusão é de profundidade extrema. Atipicamente, cada poder pode exercer as funções dos outros. E todos se autofiscalizam e fiscalizam uns aos outros, num sistema de "freios e contrapesos" que teoricamente deveria manter o equilíbrio.

O poder executivo é o legitimado a implementar as políticas públicas. Possui competência privativa de encaminhar matérias orçamentárias que instrumentalizam as políticas públicas e os programas de governo. O artigo 165 da Constituição dispõe que compete a ele a iniciativa do plano plurianual, da lei de diretrizes orçamentárias e do orçamento anual. Estes projetos de leis serão enviados ao Congresso Nacional, aplicando-se a eles as demais regras do processo legislativo.

Quando aprovadas, as políticas públicas materializam-se em leis. Nelas estarão incluídas muitas das propostas eleitorais que saíram vitoriosas, representando um movimento legítimo do regime democrático.

Ao poder executivo também compete dispor sobre a organização e funcionamento da administração pública (art. 84, VI, Constituição Federal), o que, muitas vezes, representa conduzir a estrutura burocrática própria da nossa República.

Por sua vez, ao Poder Legislativo cabe legislar sobre os mais variados assuntos do ente federativo. Ele possui ampla possibilidade de manifestação e deliberação, ressalvados os limites constitucionais significativos, como vedação de aumento de despesas em projetos de 
iniciativa exclusiva do Presidente da República (art. 63, I, CF). Atua também o Poder Legislativo no controle e fiscalização das políticas públicas com o auxílio do Tribunal de Contas da União.

Já ao Poder Judiciário compete o controle de constitucionalidade e de legalidade dos componentes das políticas públicas (atos normativos e administrativos). Eventualmente, é possível o controle de mérito desses atos quando os Poderes Executivo e Legislativo demitem-se da obrigação de tornar efetivos direitos constitucionais, abusando de seu mandato eletivo. A atuação do Poder Judiciário também tem sido considerada possível quando políticas públicas são previstas na própria Constituição, partindo-se da premissa de que a norma programática não pode ser vista como promessa constitucional inconseqüente (RE-AgR 410715/SP, 22.11.2005, Rel. Celso de Mello). Vejamos adiante mais detalhadamente este ponto.

\section{O PODER JUDICIÁRIO E AS POLÍTICAS PÚBLICAS}

A questão do controle e da intervenção do Poder Judiciário na implementação de políticas públicas já foi muito debatido na doutrina e na jurisprudência, mas ainda não se chegou a um consenso exato sobre quais os limites e formas que pode se dar.

O Supremo Tribunal Federal, no julgamento da Arguição de Descumprimento de Preceito Fundamental - ADPF - n. 45, em 29 de abril de 2004, considerou que o Poder Judiciário pode intervir no mérito das políticas públicas quando configurada "abusividade governamental".

O significado desta expressão é incerto, porém, da análise da jurisprudência recente da nossa suprema corte, conclui-se que, em casos de omissão desarrazoada do poder público, pode o juiz impor uma obrigação de fazer ao Estado a fim de efetivar direito fundamental previsto na Constituição.

Em relação ao controle judicial sobre os atos do Poder Legislativo, é tranqüilo o entendimento de que ele exerce controle de constitucionalidade das leis, via de ação ou exceção (controle direto ou controle difuso). Assim o fará também em relação ao plano plurianual, lei de diretrizes orçamentárias (LDO) e lei orçamentária anual (LOA), na qualidade de ato normativo que são.

Já em relação ao controle judicial dos atos administrativos do Poder Executivo, que importem em aplicação de políticas públicas (ou omissão de atos nesse sentido), tende a ser mais complexa a discussão. 
É certo que existe a separação de poderes, sendo função típica do Executivo a discricionariedade para a consecução das políticas públicas. Aliás, os cargos dos chefes do Executivo (Presidente da República, Governador do Estado/Distrito Federal e Prefeito) são aqueles mais próximos da população brasileira e com os quais ela mais se identifica. Assim, não seria legítimo aceitar que um juiz, que não foi eleito pelo povo, substitua a discricionariedade administrativa pela sua.

Por outro lado, pode ocorrer de um direito fundamental estar sendo tratado pelo Estado com profundo descaso e desrespeito à Constituição. Para se aferir isso, é preciso analisar o caso concreto, com dados sobre os investimentos públicos e estratégias administrativas.

Condenar simplesmente o Executivo (federal, estadual/distrital ou municipal) pelo fato de um cidadão não ter seu direito fundamental efetivado, determinando que o realize imediatamente, não é a melhor solução para a nossa República.

Antes, é indispensável que se faça uma análise de todo o contexto fático e probatório para averiguar se há realmente "abusividade governamental". Somente no caso de configuração desta abusividade é que o Poder Judiciário pode condenar o Estado interferindo na realização de uma política pública qualquer. Ou seja, devem ser verificadas as condições econômicas do ente federado, os programas de governo instituídos e o que fora posto em prática, bem como apurar improbidade administrativa e mau uso do dinheiro público.

Em muitos processos em que o Poder Judiciário interfere de forma abrupta nos planos de governo, sob o argumento de estar efetivando os direitos fundamentais, culmina por desorganizar as finanças e prejudicar a administração pública.

Como exemplo, analisemos os casos em que o judiciário tem condenado o Estado ao fornecimento de medicamentos não fornecidos pelo Sistema Único de Saúde. O fundamento é constitucional e trata-se de efetivação do direito à saúde, assegurado ao cidadão. Este direito fundamental é desdobramento do direito à vida e, portanto, está o juiz promovendo a dignidade daquela pessoa humana.

Porém, o papel do Executivo é selecionar aqueles medicamentos que vão atingir a maior parte da população para fornecê-los gratuitamente e, assim, organizar o orçamento. A realização desta lista de medicamentos do SUS, chamada RENAME, é, sem dúvidas, uma escolha trágica, tal como preconiza Wanderley Guilherme dos Santos.

Quando o judiciário determina que o Estado forneça medicamento fora daquela lista do SUS, em curto espaço de tempo, o Estado tem que adquiri-lo com dispensa de licitação, o 
que, além de ser mais oneroso, é um gasto extraordinário. Um caso não faria diferença no orçamento destinado à saúde, mas milhares destes casos podem somar um montante tão alto que inviabilize programas de governo nesta área.

De fato, esta questão das ações judiciais com pedidos de fornecimento de medicamentos tomou tamanha proporção no Judiciário Brasileiro que passou a consumir parte significativa do orçamento da saúde dos entes federados.

Notem a tragédia: o paciente necessita urgentemente do medicamento e não possui condições financeiras para comprá-lo; a saúde deste brasileiro está assegurada na Constituição Federal como direito social (direito humano de segunda geração), que requer uma atuação positiva do Estado na sua concretização; o Estado optou por não fornecer aquele medicamento (por exemplo, porque está em fase experimental, ou porque poucos são os usuários, ou porque possui um substitutivo, ...). A solução mais humana para o caso é o fornecimento imediato daquele medicamento. No entanto, a solução jurídica depende de se verificar a "abusividade governamental".

O Estado brasileiro não pode demitir-se da responsabilidade de realizar os direitos humanos, sob pena de violar a integridade da própria ordem constitucional. Portanto, o Judiciário pode intervir nos atos administrativos quando os órgãos estatais competentes estiverem descumprindo com os encargos político-jurídicos, vindo a comprometer a eficácia e a integridade de direitos fundamentais, ainda que derivados de cláusulas revestidas de conteúdo programático, já que as normas programáticas são providas de eficácia, ainda que limitada.

Não somente em relação aos chamados direitos humanos de segunda geração (direitos econômicos, sociais e culturais), que exigem uma ação positiva do Estado para sua realização, mas também quando o Estado esteja obstruindo o exercício de liberdades públicas, pode, enfim, o Poder Judiciário controlar as políticas públicas.

Negar o cumprimento de uma obrigação que tenha origem nos direitos fundamentais gera como consequiência verdadeira renúncia em reconhecê-los.

Apesar de ser conhecida a "teoria da reserva do possível", principalmente em um Estado em desenvolvimento como o nosso, a liberdade de atuação do Poder Público não é absoluta. Ela é toda pautada e limitada pela Constituição Federal, que inclusive lhe impõe metas de curto e longo prazo.

A Constituição de 1988 descreve um Estado Democrático que se propõe a assegurar e a promover a dignidade humana. Portanto, este é o alvo prioritário dos gastos públicos. 
Cabe ao Poder Judiciário, diante de um litígio do indivíduo contra o Estado, ponderar a razoabilidade da pretensão deduzida em relação à disponibilidade do Poder Público para atendê-la.

\section{CONCLUSÃO}

Vimos que as políticas públicas são programas de governo e ações do poder público, visando à realização dos direitos fundamentais, geralmente associadas a aprimorar aspectos sociais, econômicos ou políticos da comunidade, previstos principalmente em nossa Carta Magna.

Tipicamente, compete ao Poder Legislativo e ao Poder Executivo decidir sobre as prioridades sociais, concretizando as políticas públicas em atos normativos e administrativos. Vimos que não é fácil a tarefa de percepção das prioridades dentre as demandas sociais.

Porém, essa liberdade de percepção da realidade e aplicação dos recursos públicos pelo administrador e pelo legislador não é ilimitada. Encontra suas principais diretrizes na Constituição Federal, como não poderia deixar de ser, mas também na motivação dos atos, na observância do princípio da legalidade, no uso regular do dinheiro público e etc.

Além do autocontrole exercido por cada poder do Estado, também eles se fiscalizam mutuamente e ainda temos o Tribunal de Contas da União que exerce relevantíssima função no controle dos gastos públicos.

O Poder Judiciário não está afastado de controlar as políticas públicas por causa do princípio da separação dos poderes ou por motivos da inviolabilidade da discricionariedade administrativa ou da reserva do possível.

Vimos que o Poder Judiciário pode e deve intervir nas políticas públicas (ou na falta delas) quando houver abusividade governamental, que significa nada menos que desrespeito à Constituição na forma de governar.

A experiência nos mostra que as políticas públicas podem ser promovidas por meio da jurisdição, o que muito contribui com a realização dos direitos fundamentais.

\section{REFERÊNCIAS BIBLIOGRÁFICAS}

AITH, Fernando. Políticas públicas de estado e de governo: instrumentos de consolidação do estado democrático de direito e de promoção e proteção dos direitos humanos. In: BUCCI, 
Maria Paula Dallari (org). Políticas Públicas: reflexões sobre o conceito jurídico. São Paulo: Saraiva, 2006, p. 217-245.

BUCCI, Maria Paula Dallari. O conceito de política pública em direito. In: BUCCI, Maria Paula Dallari (org). Políticas Públicas: reflexões sobre o conceito jurídico. São Paulo: Saraiva, 2006, p. 1-49.

FREITAS, Riva Sobrado de. Aspectos do estado contemporâneo e desafios na formulação das políticas sociais. Sequencia - Estudos jurídicos e políticos - Revista do Curso de Pósgraduação em Direito da UFSC, ano XXVII, dez/2008, p. 31-46.

MASSA-ARZABE, Patrícia Helena. Dimensão jurídica das políticas públicas. In: BUCCI, Maria Paula Dallari (org). Políticas Públicas: reflexões sobre o conceito jurídico. São Paulo: Saraiva, 2006, p. 51-74.

SANTOS, Wanderley Guilherme dos. A trágica condição da política social. In:

ABRANCHES, Sérgio Henrique et tal. Política social e combate à pobreza. Rio de Janeiro: Jorge Zahar Editor, $4^{\text {a }}$ ed., 1998, p. 33-63.

SILVA, Christian Luiz da. LIMA, José Edmilson de Souza. (org) Políticas públicas e indicadores para o desenvolvimento sustentável. São Paulo: Saraiva, 2010.

VIEIRA JUNIOR, Ronaldo Jorge Araujo. A Advocacia Pública Consultiva Federal e a sustentabilidade jurídico-constitucional das políticas públicas: dimensões, obstáculos e oportunidades na atuação da Advocacia-Geral da União. Revista da Advocacia-Geral da União. Ano VIII. Número 19. jan/mar 2009. Brasília-DF, p. 9-40. 